\title{
A emergência da autoria na arte popular portuguesa: o contributo de Ernesto de Sousa ${ }^{1}$
}

\author{
Maria Manuela Restivo \\ FLUP/Doutoramento em Estudos do Património (DEP) \\ mariamanuelarestivo@gmail.com
}

\section{Resumo}

No presente capítulo procura-se dar conta do momento em que, na arte popular portuguesa, emerge a figura do autor, contrariando a ideia até então dominante de que a arte popular se definia como uma criação coletiva. Esta mudança de perspetiva, ocorrida em meados da década de 1950, tem como um dos principais protagonistas Ernesto de Sousa, artista e teórico de arte. A partir da análise do trabalho deste autor sobre arte popular portuguesa, defende-se simultaneamente a singularidade do seu pensamento sobre arte popular, quando comparado com os seus contemporâneos, e a importância do seu contributo na inauguração de uma nova forma de perspetivar esta produção artística em Portugal.

Palavras-chave: arte popular, autoria, Ernesto de Sousa, Portugal

The emergence of authorship in Portuguese folk art: the contribution of Ernesto de Sousa

\begin{abstract}
In this chapter, I seek to account for the moment when, in Portuguese folk art, the figure of the author emerges, contradicting the previous dominant idea that folk art was defined by a collective creation. This change in perspective, which occurred in the mid1950s, has Ernesto de Sousa, an artist and art theorist, as one of the main protagonists. Based on the analysis of this author's work on Portuguese folk art, I advocate the singularity of his thinking on folk art, when compared with his contemporaries, and the importance of his contribution in the inauguration of a new way of looking at this artistic production in Portugal.
\end{abstract}

Keywords: folk art, authorship, Ernesto de Sousa, Portugal

\footnotetext{
${ }^{1} \mathrm{O}$ presente artigo é uma reflexão provisória de uma investigação de doutoramento em curso sobre a construção social da arte popular portuguesa, que conta com o apoio de uma bolsa da Fundação para a Ciência e Tecnologia, referência SFRH/BD/129435/2017.
} 
Restivo, Maria Manuela (2020). A emergência da autoria na arte popular portguesa: o contributo de Ernesto de Sousa. In Alice Duarte (ed.), Seminários DEP/FLUP vol. 1. Porto: Universidade do Porto, Faculdade de Letras/DCTP, p. 98-117. https://doi.org/10.21747/9789898969682/seminariosv1a5

\section{Introdução}

O conceito de arte popular sempre constituiu um conceito problemático, sujeito a interpretações diversas e frequentemente contraditórias ${ }^{2}$. Uma aproximação ao conceito revela rapidamente uma falta de consenso generalizado entre os diferentes autores que sobre ela se debruçaram, detetando-se diferenças significativas que variam ao longo da história, mas também entre diferentes tradições nacionais e mesmo entre autores contemporâneos entre si. Assim, se para alguns ela é ancestral (Chaves, 1943; Correia, 1916), para outros pode ser contemporânea (Shelton, 2015); se uns defendem a sua ligação à ruralidade, outros incluem as expressões urbanas (Canclini, 1989; Shelton, 2015); se uns a veem como uma criação anónima (Leite de Vasconcelos, 19331988; Correia, 1916; Chaves, 1943), para outros ela é fruto de autores individuais (Sousa, 1987). Tal disparidade de perspetivas levou Valérie Rousseau (2012) a considerar o conceito de arte popular como camaleónico, capaz de se adaptar a diferentes situações e contextos, ao invés de se procurar a sua redução a uma designação consensual. Importa, consequentemente, perceber que o desenvolvimento do conceito apresenta lugares concretos de circulação e enunciação, intimamente relacionado com circunstâncias políticas, sociais e ideológicas que é importante detetar. Tal possibilita afirmar - facto que a investigação em curso permite corroborar - que a forma como o conceito se desenvolveu em Portugal apresenta as suas especificidades próprias, nem sempre condizentes com o que ocorria noutros contextos nacionais, ainda que com estes apresentando por vezes continuidades significativas.

\section{A posição ambígua da arte popular}

As diferentes conceções de arte popular que acima se enunciaram não se situam unicamente num plano teórico de conceptualização do conceito. Elas refletem-se na forma de perspetivar objetos e artistas, na institucionalização dos objetos em circuitos museológicos e na circulação dos mesmos em sistemas de compra e venda, isto é, nos

\footnotetext{
${ }^{2}$ No presente texto, arte popular inclui apenas as artes plásticas, já que se considera que a música, a dança, a literatura e a arquitetura encontram domínios específicos de formulação, e por isso devem ser entendidos no seu campo próprio.
} 
Restivo, Maria Manuela (2020). A emergência da autoria na arte popular portguesa: o contributo de Ernesto de Sousa. In Alice Duarte (ed.), Seminários DEP/FLUP vol. 1. Porto: Universidade do Porto, Faculdade de Letras/DCTP, p. 98-117. https://doi.org/10.21747/9789898969682/seminariosv1a5

lugares de consumo dos objetos. Trata-se, no fundo, do que se pode designar, seguindo Becker (2010), como o mundo da arte popular. À semelhança do que acontece com outras formas artísticas, estes circuitos operam formas de inclusão e exclusão, ditando o que deve ser caracterizado como arte popular e o que deve ficar de fora desta categoria. Esta situação é especialmente evidente nos contextos de recolha de objetos concretizada por instituições museológicas, cujas coleções de "arte popular" podem ser constituídas por objetos muito distintos entre si - basta comparar alguns museus dos Estados Unidos da América (por exemplo o Museu de Arte Moderna de Nova lorque), onde as coleções apresentam obras de indivíduos autodidatas, com os seus congéneres europeus, onde estas são essencialmente compostas por objetos da vida rural.

Paralelamente, a arte popular sofre da mesma ambiguidade da anteriormente denominada arte primitiva ou tribal, que oscilava entre a categoria de artefacto ou arte (Vogel, 1988): na generalidade, se, no primeiro caso, os objetos são sobretudo encarados como documentos que permitem conhecer as sociedades nos quais circulam, habitando os museus etnográficos, no segundo eles são valorizados maioritariamente pelas suas qualidades estéticas, circulando frequentemente nos circuitos artísticos de museus e galerias de arte.

Também no contexto português se deteta esta posição ambígua da arte popular, presente quer nas formas como esta é conceptualizada, quer nos lugares onde circula. O presente capítulo procura focar-se precisamente no momento em que se deteta, na arte popular portuguesa, a emergência de uma visão autoral, contrariando as perspetivas anteriormente vigentes que encaravam a arte popular sobretudo como uma produção coletiva. Reconhecendo-se que esta rutura se deve a circunstâncias sociais e políticas complexas - e não unicamente à ação de atores particulares - importa, porém, investigar o pensamento e ação de indivíduos concretos, percebendo a singularidade dos contributos daí resultantes. Examina-se neste capítulo a forma como Ernesto de Sousa, através da sua investigação, textos e exposições, desenvolveu e consolidou uma perspetiva em que a arte popular portuguesa passa a ser vista como composta por diferentes autores individuais. 
Restivo, Maria Manuela (2020). A emergência da autoria na arte popular portguesa: o contributo de Ernesto de Sousa. In Alice Duarte (ed.), Seminários DEP/FLUP vol. 1. Porto: Universidade do Porto, Faculdade de Letras/DCTP, p. 98-117. https://doi.org/10.21747/9789898969682/seminariosv1a5

\section{Breve genealogia da arte popular portuguesa}

À semelhança do que aconteceu noutros países europeus, também em Portugal a valorização da arte popular ocorreu em finais do século XIX. Datam de meados desse século as primeiras recolhas de contos tradicionais, com Teófilo Braga e Adolfo Coelho, paralelas à exaltação dos valores do "povo" por parte de escritores como Almeida Garrett e Ramalho Ortigão. Caberá a José Leite de Vasconcelos fazer a transição da tradição oral à cultura material (Leal, 2004): o seu projeto de estudo do povo português na sua totalidade, bem como nas dimensões passado-presente (através da conjugação da arqueologia e da etnografia), resultará numa atenção dada à cultura material em finais do século XIX, de certa forma ainda inédita no contexto português. Ele será um dos investigadores que primeiramente chamará a atenção para a dimensão estética dos objetos "etnográficos", começando pela ornamentação das cangas de bois (Leite de Vasconcelos, 1881) e abarcando temas tão diversos como as louças, as carrancas das fontes, as vasilhas de barro, os barcos de Aveiro, etc., que compilou no seu Boletim de Etnografia (1920-1938), que pode ser considerado um dos primeiros "manuais" da cultura material vernacular portuguesa. O Museu Etnológico Português, por si criado em 1893, guarda ainda hoje a primeira coleção de objetos de produção popular constituída em Portugal, denominada durante algum tempo como a secção das "Belas Artes Populares", inserida na secção de etnografia (Leite de Vasconcelos: 1915).

A par de Leite de Vasconcelos, é obrigatória a referência a Joaquim de Vasconcelos, ainda para o período de finais do século XIX. Este historiador da arte será responsável pelo enaltecimento dos objetos de produção popular, não tanto sob o ponto de vista do estudo do povo português - ainda que a importância deste não lhe seja alheia - mas antes ecoando o movimento Arts and Crafts, que defendia, em traços gerais, que o futuro da produção industrial deveria surgir das formas e materiais vernaculares de cada país (Morris, 2003). As exposições que organizou, dedicadas a diferentes artes decorativas, juntavam objetos vernaculares com objetos de produção industrial (Leandro, 2014), numa perspetiva que antecipava as preocupações da disciplina do design, que só muito mais tarde veria o seu estabelecimento em Portugal. A sua visão sobre esta temática resultaria na criação do Museu Industrial do Porto e de 
Restivo, Maria Manuela (2020). A emergência da autoria na arte popular portguesa: o contributo de Ernesto de Sousa. In Alice Duarte (ed.), Seminários DEP/FLUP vol. 1. Porto: Universidade do Porto, Faculdade de Letras/DCTP, p. 98-117. https://doi.org/10.21747/9789898969682/seminariosv1a5

Lisboa (1883); porém, estes Museus durariam apenas alguns anos, encerrando em 1899, e as suas coleções foram sendo dispersadas ao longo dos anos seguintes (Leandro, 2014). Apesar da sua relevância, a perspetiva inédita de Joaquim de Vasconcelos não encontrou seguidores, tratando-se de uma linha de ação com poucas continuidades.

As primeiras três décadas do século XX são marcadas por uma certa dispersão no que diz respeito às iniciativas voltadas para a arte popular. O Museu Etnológico permanecerá como uma instituição central no colecionismo desta tipologia de objetos -ainda que esta atividade não seja acompanhada da pesquisa que seria desejável - já que o Museu se tinha orientado para a investigação e recolha arqueológica. Esta época - que balizamos até ao aparecimento do Secretariado de Propaganda Nacional (SPN) em 1933, que irá implementar uma nova política cultural - caracteriza-se sobretudo pela publicação de alguns textos sobre arte popular, resultantes das investigações de um conjunto de autores sobre esta matéria, destacando-se Rocha Peixoto, Vergílio Correia, Sebastião Pessanha e Luís Chaves ${ }^{3}$. Ainda que cada um tenha as suas especificidades e linhas de pensamento próprias, foram estes autores que, pelas suas investigações e iniciativas, contribuíram para a sedimentação do campo da arte popular portuguesa, desempenhando um papel essencial na identificação de manifestações e produtos, no seu mapeamento ao longo do país, na comparação com realidades estrangeiras (com destaque para a comparação com a arte popular italiana que Vergílio Correia (1916) realizou), na procura da origem de determinadas formas ou motivos e na reflexão sobre o próprio conceito de arte popular e seus significados.

A Rocha Peixoto se atribui um trabalho exímio na análise de certas manifestações de arte popular, numa perspetiva ampla que abarca as origens, a descrição minuciosa de materiais, técnicas, formas e motivos, (vide a sua investigação sobre ourivesaria), bem como uma preocupação com a condição social do produtor - algo que não encontra paralelo em nenhum autor (cf. Peixoto, 1995). Vergílio Correia e Sebastião Pessanha são responsáveis pela constituição da revista Terra Portuguesa (1916-1927), que vão

\footnotetext{
${ }^{3}$ Foram vários os autores que na época se debruçaram por temas muito diversos dentro da arte popular, muitas vezes dedicando-se à investigação sobre manifestações das suas próprias regiões. Poder-se-ia, por exemplo, mencionar Emanuel Ribeiro, Cláudio Basto, Rocha Madahil, Aarão de Lacerda, etc. Contudo, são os autores anteriormente citados que apresentam uma maior relevância, quer em termos de quantidade de produção escrita, quer no seu conteúdo, quer pelas ações paralelas realizadas.
} 
Restivo, Maria Manuela (2020). A emergência da autoria na arte popular portguesa: o contributo de Ernesto de Sousa. In Alice Duarte (ed.), Seminários DEP/FLUP vol. 1. Porto: Universidade do Porto, Faculdade de Letras/DCTP, p. 98-117. https://doi.org/10.21747/9789898969682/seminariosv1a5

alimentando com inúmeros artigos dedicados à arte popular ${ }^{4}$. Os membros desta revista são também responsáveis pela organização de uma exposição, ocorrida em 1917, dedicada aos tapetes de Arraiolos, que condensa o estudo histórico dos tapetes com uma vontade de revitalização da sua técnica, inaugurando uma certa preocupação patrimonial com as artes e ofícios portugueses.

Luís Chaves, essa figura “injustamente esquecida” (Bragança, 2016), apresenta um contributo essencial, quer nas investigações que começa a realizar sobre as coleções do Museu Etnológico, quer, mais tarde, na sua colaboração com o SPN/SNI, mais concretamente no papel proeminente que desempenhou na construção de exposições e catálogos que este organismo realiza sobre arte popular (ver Chaves 1914; 1936; 1940). Porém, este autor, à semelhança de outros da sua geração, assume constantemente um registo de exaltação patriótica da arte popular, exaltando as suas qualidades em descrições poéticas dos objetos, escondendo um certo paternalismo para com este tipo de produção artística.

Curiosamente, todos estes autores estão ligados à prática de colecionismo, institucional ou privado: Rocha Peixoto recolhe objetos para o Museu Municipal do Porto; Vergílio Correia e Luís Chaves, no âmbito do Museu Etnológico, com o qual mantiveram vínculos profissionais; e Sebastião Pessanha enquanto colecionador privado, podendo mesmo ser considerado um dos primeiros colecionadores (privados) de arte popular portuguesa. Tal implica que, no caso português, em continuidade com outros contextos, a valorização da arte popular se dá em diversas dimensões: a investigação, plasmada em inúmeros artigos e publicações; a aquisição dos objetos, que enriquece museus e coleções privadas; e a exposição, lugar essencial de apresentação dos objetos aos públicos, com vista à disseminação de narrativas específicas. Estas são, aliás, três dimensões inerentes ao processo de patrimonizalização e musealização de qualquer tipologia de objetos.

A criação, em 1933, do Secretariado de Propaganda Nacional (SPN) - organismo do regime do Estado Novo, dedicado à criação de políticas culturais para o país contribuirá simultaneamente para a institucionalização da arte popular (através da

\footnotetext{
${ }^{4}$ Como por exemplo os textos de Vergílio Correia sobre "'Cassoiros' do Baixo Alentejo", (1916b), os "Brinquedos de Louça de Estremoz" (1916c) ou os Tarros do Alentejo e da Beira-Baixa" (1916d); e os de Sebastião Pessanha dedicados à fiação e à tecelagem manuais (1916).
} 
Restivo, Maria Manuela (2020). A emergência da autoria na arte popular portguesa: o contributo de Ernesto de Sousa. In Alice Duarte (ed.), Seminários DEP/FLUP vol. 1. Porto: Universidade do Porto, Faculdade de Letras/DCTP, p. 98-117. https://doi.org/10.21747/9789898969682/seminariosv1a5

criação do Museu de Arte Popular) e para a sedimentação de uma conceção específica desta forma artística: de expressão coletiva, associada a regiões concretas, tradicional e ancestral, e que é necessário proteger de influências externas. Mais do que criar novas perspetivas sobre a arte popular, o Estado Novo concretizou a sua visualização: a sua ação no que diz respeito a esta forma de arte prende-se com a criação de iniciativas de carácter fortemente visual e/ou performativo, o que no caso da arte popular resultou na concretização de diversas exposições, nacionais e internacionais, que culminou na criação do já mencionado Museu de Arte Popular. Como já foi amplamente apontado por alguns autores (Alves, 2013; Melo, 2001), a visão da arte popular que o Estado Novo fabricou estava intimamente ligada com a componente ideológica do regime, que procurava exaltar a ruralidade e a nacionalidade, rejeitando o cosmopolitismo associado à vida urbana. O camponês é transformado em esteta, sendo valorizados com particular ênfase os objetos coloridos e profusamente enfeitados (Alves, 2013). Estes, porém, eram sempre exibidos enquanto produções anónimas e os nomes dos produtores dos objetos raramente apareciam nas exposições e nas publicações.

\section{A ideia de autoria na arte popular portuguesa}

É em meados da década de 1950 que surge em Portugal uma visão da arte popular radicalmente diferente da até então existente. Ela apresenta dois protagonistas principais: António Quadros e Ernesto de Sousa. Estas duas figuras são fundamentais para uma mudança de perspetiva na forma de encarar a arte popular: de uma arte anónima e coletiva passa-se a conceber uma arte popular de autor, ligada ao aparecimento de nomes concretos. Estas duas figuras introduzem uma certa rotura na forma de perspetivar a arte popular portuguesa; por um lado, porque surgem no contexto das Belas Artes, o que implicou uma preocupação primeiramente estética com os objetos encontrados. Por outro lado, estes autores não se filiam nos textos etnográficos escritos pelas gerações anteriores, desconhecendo-os ou simplesmente descartando a sua importância.

O nome de António Quadros, no campo da arte popular, liga-se forçosamente a Rosa Ramalho: foi ele quem, na feira das Festas da Nossa Senhora da Saúde, no Porto, 
Restivo, Maria Manuela (2020). A emergência da autoria na arte popular portguesa: o contributo de Ernesto de Sousa. In Alice Duarte (ed.), Seminários DEP/FLUP vol. 1. Porto: Universidade do Porto, Faculdade de Letras/DCTP, p. 98-117. https://doi.org/10.21747/9789898969682/seminariosv1a5

em meados da década de 1950 (Restivo, 2016) "descobre"5 esta ceramista que, como tantas outras, vendia as suas peças de barro num circuito de feiras pelo norte do país. António Quadros terá ficado fascinado com a originalidade das peças de Rosa Ramalho. Após encontros sucessivos com a ceramista - levando, inclusivamente, um grupo de alunos seus da Faculdade de Belas Artes a frequentar com frequência a sua casa-oficina - Quadros aconselha Rosa Ramalho a assinar as suas peças (idem).

Uma perspetiva semelhante encontra-se em Ernesto de Sousa: em vez de procurar na arte popular exemplares de uma tipologia, como operava a equipa do Estado Novo - procurando tipos específicos de cestos, têxteis ou mobiliário - este autor vai procurar a singularidade dentro da estética popular.

\section{A arte popular em Ernesto de Sousa}

Ernesto de Sousa é consensualmente considerado uma das principais figuras do século XX português, no que ao campo artístico e cultural diz respeito. Nascido em abril de 1921, constitui-se como uma figura fundamental do modernismo português, modernismo que entendia enquanto ideologia e não definido temporalmente (Santos, 2007). Foi José Augusto França (1997), que o conhecia de perto, quem melhor condensou uma caracterização deste autor, evidenciando o seu percurso (e carácter) multifacetado: "José Ernesto de Sousa, crítico de arte e de cinema, e cineasta, animador de cineclubes, fundador de um dos primeiros, proibido depois, homem de vários interesses culturais, aventureiro de imaginação, viajante com amizades por todo o lado, tão falador como homem de trabalho afincado, constante em opções políticas de esquerda, mais ou menos extremada, companheiro de ações no terreno, colecionador de imagens e documentos, escritor, poeta, jornalista, editor, ao longo de uma vida bem vivida, em sua liberdade e boémia fantasia" $(1997: 37,38)$. De facto, das várias pessoas que sobre ele escreveram - e foram bastantes - não há quem não sublinhe a multiplicidade de assuntos e temas a que se dedicou, fazendo-o, dizem os que o

\footnotetext{
${ }^{5}$ O termo "descoberta" é usualmente utilizado no campo artístico para designar o momento em que determinado artista se torna conhecido de uma audiência mais alargada, entrando nos circuitos do mundo da arte (Becker, 2010). É interessante notar como na bibliografia sobre este assunto, se tem sedimentado esta forma de contar a história, a "descoberta" de Rosa Ramalho por António Quadros.
} 
Restivo, Maria Manuela (2020). A emergência da autoria na arte popular portguesa: o contributo de Ernesto de Sousa. In Alice Duarte (ed.), Seminários DEP/FLUP vol. 1. Porto: Universidade do Porto, Faculdade de Letras/DCTP, p. 98-117. https://doi.org/10.21747/9789898969682/seminariosv1a5

conheceram pessoalmente, de forma arrebatada e apaixonada. Ernesto de Sousa, porém, nunca se vinculou a nenhum organismo específico, antes se concretizando, pessoal e profissionalmente (não havia, para ele, divisão entre vida e trabalho) em diferentes projetos artísticos, editoriais ou expositivos, no que hoje denominaríamos como investigador e/ou curador independente - sendo também neste aspeto um pioneiro em Portugal ${ }^{6}$.

Não sendo possível neste contexto enunciar com pormenor os diferentes trabalhos a que se dedicou ao longo da vida, tal foi a sua diversidade e heterogeneidade, importa, contudo, mencionar que se interessou, numa primeira fase, pelo cinema, desenvolvendo a atividade de crítico e realizador ${ }^{7}$; numa segunda fase, desenvolveu investigação sobre arte popular, publicando alguns textos e realizando algumas exposições; numa terceira fase, abraçou a vanguarda da arte contemporânea, e o seu nome ficou definitivamente associado à "chegada" do movimento da arte conceptual a Portugal, trazendo e partilhando ideias com as quais contactava no estrangeiro, convidando artistas a apresentar os seus trabalhos no país, e realizando exposições (as primeiras) que se debruçavam sobre as manifestações deste movimento em Portugal, com destaque para a exposição "Alternativa Zero" (1977). Esta última fase do seu percurso profissional tem vindo a ser amplamente documentada nos últimos anos, incentivada pela organização de algumas exposições consagradas à importância do seu trabalho para o desenvolvimento da arte contemporânea em Portugal: Itinerários na Galeria Almada Negreiros, Lisboa (1987), e postumamente Perspectiva: Alternativa Zero (1997) na Fundação de Serralves e Revolution my Body (1998) no Centro de Arte Moderna. Também a área que aqui interessa explorar - a sua relação com a arte popular - tem sido alvo de atenção nos últimos anos, nomeadamente por João Leal (2004) Mariana Pinto dos Santos (2007), e Nuno Faria (2014).

\footnotetext{
${ }^{6} \mathrm{~A}$ própria heterogeneidade do seu percurso, reforçada por vários autores que se debruçaram sobre a sua obra (Fernandes (1997), Santos (2007), Wandschneider (1998), tem sido alvo de problematização, já que Ernesto de Sousa passa de um neorrealista militante, na sua juventude, para uma convicta defesa das artes conceptuais e experimentais, a partir da década de 1960-70, dois movimentos usualmente vistos como antagónicos.

${ }^{7}$ Esta fase é marcada pela investigação e crítica de filmes, pela criação de revistas de cinema, pela militância cineclubista e pela própria vontade de fazer cinema, que culmina na realização do filme $D$. Roberto, que estreia em 1962.
} 
Restivo, Maria Manuela (2020). A emergência da autoria na arte popular portguesa: o contributo de Ernesto de Sousa. In Alice Duarte (ed.), Seminários DEP/FLUP vol. 1. Porto: Universidade do Porto, Faculdade de Letras/DCTP, p. 98-117. https://doi.org/10.21747/9789898969682/seminariosv1a5

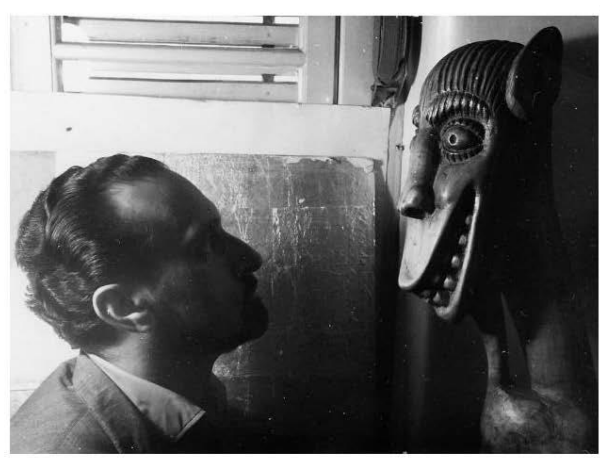

Imagem 1. Ernesto de Sousa com escultura de Franklin, c. 1964 https://www.ernestodesousa.com/biografia Cortesia CEMES/Espólio Ernesto de Sousa

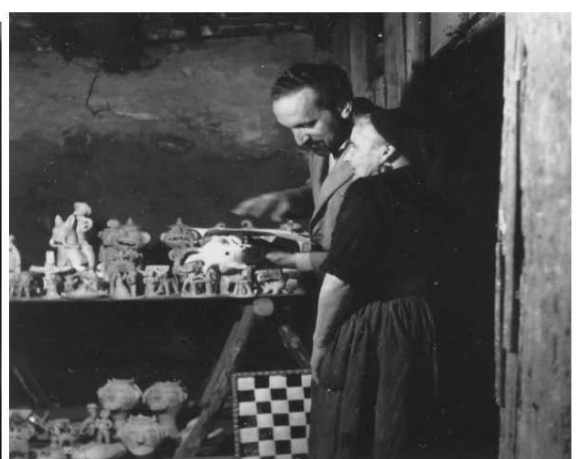

Imagem 2. Ernesto de Sousa com Rosa Ramalho na sua oficina, c. 1964 https://www.ernestodesousa.com/biografia Cortesia CEMES/Espólio Ernesto de Sousa

Segundo Miguel Wandschneider (1998), o interesse pela arte popular deteta-se logo em 1944, numa carta que escreve a Eduardo Calvet de Magalhães:

ofereceram-me recentemente uma estatueta em madeira moçambicana. Estou maravilhado com ela. Despertou em mim definitivamente a paixão pela arte indígena. Manda-me se puderes o que aí houver: madeira, osso, metais, adorno em geral, etc. Aquele colar de contas vermelho e preto vai para o meu museu de arte popular. Calcula a sua importância se eu te disser que no Paleolítico (pedra lascada) já o homem fazia colares semelhantes, com conchas e sementes. Sabes que um dos métodos de estudo da pré-história é a comparação com os primitivos, comparação com as manifestações populares e as infantis. De resto, aprecio essas coisas sobretudo sob o seu aspeto artístico, é claro. (1998: 39)

Esta primeira referência de Ernesto de Sousa à arte popular é significativa em vários aspetos: há uma correspondência, na conceção do autor, entre as artes "primitivas" ou tribais e as artes populares; há um interesse em colecionar essas peças; e, sobretudo, constata-se desde logo que o seu interesse perante estas formas é predominantemente artístico, ou seja, ligado ao aspeto estético dos objetos.

Este interesse pelas artes não eruditas tem a sua primeira materialização na Exposição de Arte Negra, de 1946, que realiza em colaboração com Diogo de Macedo, e se concretiza no âmbito da Semana de Arte Negra da Escola Superior Colonial (Wandschneider 1998: 40). Esta exposição procurava estabelecer relações entre a arte africana e a arte moderna, expondo peças africanas pertencentes à Sociedade de Geografia de Lisboa ao lado de obras da arte moderna portuguesa: "um desenho de Modigliani, alguns desenhos de Almada Negreiros e um quadro, por este emprestado, de Amadeo de Souza-Cardoso, assim como reproduções de obras de artistas como 
Restivo, Maria Manuela (2020). A emergência da autoria na arte popular portguesa: o contributo de Ernesto de Sousa. In Alice Duarte (ed.), Seminários DEP/FLUP vol. 1. Porto: Universidade do Porto, Faculdade de Letras/DCTP, p. 98-117. https://doi.org/10.21747/9789898969682/seminariosv1a5

Picasso e Matisse" (idem, 40) ${ }^{8}$. Apesar de ter acontecido num lugar relativamente marginal, esta exposição constituiu a primeira deste género em Portugal sob dois aspetos fundamentais: pelo cruzamento entre as artes moderna e africana; e por perspetivar a última de um ponto de vista estético, e não "etnográfico", tal como se vinha a realizar em alguns museus, nomeadamente na Sociedade de Geografia de Lisboa (Santos, 2007) ${ }^{9}$.

Ainda que não se tivesse dedicado logo ao estudo da arte popular - algo que só veio a decorrer no final da década de 1950 - deteta-se com frequência em Ernesto de Sousa o seu interesse pela temática, de forma ou mais menos explícita: por exemplo, nos álbuns fotográficos de obras de arte popular que foi produzindo ao longo da vida; na realização do documentário "O Natal na arte Portuguesa” (1954), que o leva a estudar os cruzamentos entre arte erudita e popular ao longo do tempo (Santos, 2007); ou no próprio Dom Roberto, o seu filme mais consagrado, onde explora uma forma de teatro popular português.

Em 1964, no contexto da intensificação das pesquisas que vai realizando sobre a escultura portuguesa, que começam por resultar nos textos que produz para a revista Seara Nova (Santos, 2014), Ernesto de Sousa realiza uma exposição dedicada a quatro artistas populares do norte de Portugal: Rosa Ramalho, Mistério, Franklin Vilas Boas e Quintino Vilas Boas. A exposição - intitulada Barristas e Imaginários: quatro artistas populares do Norte - decorre na livraria Divulgação e recorre a uma museografia rudimentar, que se serve de tijolos e tábuas de madeira como expositores (cf. Faria, 2014). As peças dos diferentes artistas são expostas, procurando-se sobretudo demonstrar as qualidades formais dos objetos em exposição. Esta exposição surge após o estabelecimento de uma relação pessoal que Ernesto de Sousa desenvolve com cada um dos quatro artistas populares, nomeadamente com Rosa Ramalho e Franklin Vilas Boas (Wandschneider, 1998:67). Se a "descoberta" de Rosa Ramalho é atribuída, pelo próprio Ernesto de Sousa, a António Quadros, a de Franklin Vilas Boas é atribuída a si próprio. Significativo é o facto de Ernesto de Sousa, durante o ano de 1964, atribuir uma

\footnotetext{
${ }^{8}$ Foi no âmbito desta exposição que Ernesto de Sousa iniciaria uma relação - que se revelaria longa - quer com Almada, quer com José Augusto França (cf. Wandschneider, 1998).

${ }^{9}$ Porém, não podemos deixar de sublinhar o atraso desta exposição em relação às suas congéneres europeias, onde já em princípios do século XX, no âmbito dos movimentos cubista e dadaísta, este tipo de cruzamentos era frequente.
} 
Restivo, Maria Manuela (2020). A emergência da autoria na arte popular portguesa: o contributo de Ernesto de Sousa. In Alice Duarte (ed.), Seminários DEP/FLUP vol. 1. Porto: Universidade do Porto, Faculdade de Letras/DCTP, p. 98-117. https://doi.org/10.21747/9789898969682/seminariosv1a5

avença mensal a Franklin, com vista a proteger a sua produção de influências externas que poderiam, segundo o autor, conduzir à "aculturação" da sua obra, algo que se deveria procurar evitar. Após a exposição, Ernesto de Sousa vende alguns objetos dos artistas, principalmente no Porto e em Lisboa, pensando inclusivamente em profissionalizar a comercialização de escultura popular através de uma galeria, algo que nunca se veio a concretizar (idem, 1998).
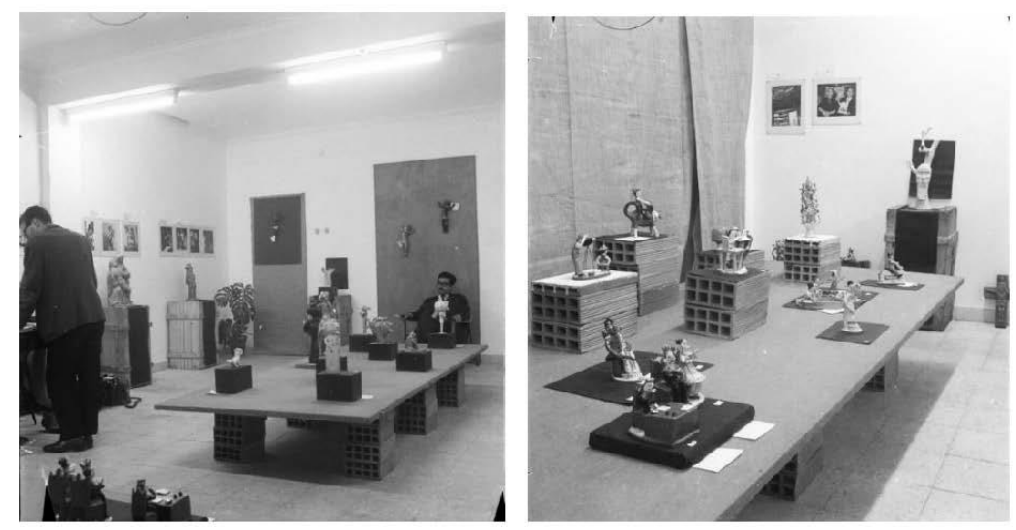

Imagens 3 e 4. Exposição Barristas e Imaginários: Quatro Artistas Populares do Norte https://www.ernestodesousa.com/projectos/barristas-e-imaginarios-quatro-artistaspopulares-do-norte

Cortesia CEMES/Espólio Ernesto de Sousa

Em 1965, no ano a seguir à exposição, publica "Para o estudo da escultura portuguesa", um livro-álbum que combina texto e imagem, refletindo o trabalho de recolha de imagens a que Ernesto de Sousa se tinha dedicando previamente - quer de imagens de arquivo, quer de fotografias que o próprio efetuou ao longo do tempo, acompanhado de trechos textuais, por vezes de carácter mais histórico, outras mais poético ${ }^{10}$. O objetivo do livro consiste na documentação da escultura portuguesa apresentando já um especial enfoque na escultura de expressão popular - através do método que utilizará em anos seguintes: a manipulação fotográfica como ferramenta de investigação estética, através de cortes, reduções ou ampliações. As evidências que a fotografia revelaria através da sua manipulação permitiria traçar uma certa essência da escultura portuguesa. Nesta publicação, a arte popular surge em diálogo com outras

\footnotetext{
${ }^{10}$ Não consegui identificar com precisão o momento em que Ernesto de Sousa se começa a dedicar ao estudo da escultura popular, mas parece que terá sido um tema que desde cedo acompanhou e, à semelhança de outros, foi condensando em álbuns fotográficos que ia realizando.
} 
Restivo, Maria Manuela (2020). A emergência da autoria na arte popular portguesa: o contributo de Ernesto de Sousa. In Alice Duarte (ed.), Seminários DEP/FLUP vol. 1. Porto: Universidade do Porto, Faculdade de Letras/DCTP, p. 98-117. https://doi.org/10.21747/9789898969682/seminariosv1a5

formas de expressão escultórica, sejam formas eruditas, históricas ou africanas, procurando-se as semelhanças e os pontos de contacto. Este gesto de comparação niveladora das artes populares e eruditas só encontrará paralelo em Portugal muito mais tarde, com as exposições de Paulo Mendes e Nuno Faria ${ }^{11}$.

No ano de 1966, Ernesto de Sousa ganha uma bolsa de um ano da Fundação Calouste Gulbenkian, precisamente para o estudo da "escultura portuguesa de expressão popular", que depois se renovará por 1967. Esta deve incluir não só a arte popular atual, mas também a histórica, sendo que Ernesto de Sousa é especialmente atento à escultura românica e antiga, que denomina "arcaizante" (cf. Sousa (2014) [1966], 86). Surge, assim, a oportunidade de consolidar e aprofundar quer uma temática, quer uma metodologia de pesquisa que foi desenvolvendo informalmente em anos prévios, e que havia sido "experimentada" já na publicação de "Para o estudo da escultura portuguesa". Através dos relatórios que escreveu para a Fundação Calouste Gulbenkian, é possível aceder aos objetivos de Ernesto de Sousa, bem como às principais referências teóricas e metodológicas de que se socorre de forma algo desprendida e até, de um certo ponto de vista, leviana, como era, aliás, característico de todo o seu trabalho de pesquisa ${ }^{12}$. É o próprio que o admite quando afirma: "não nos preocupou a realização de uma mistura eclética de conceitos e métodos" (idem, 55).

Mas qual é exatamente o pensamento sobre arte popular que Ernesto de Sousa desenvolve? Através da leitura dos seus textos que se debruçam sobre a arte popularque, como todos os seus textos, são escritos num registo provocatório e aberto, sugerindo reflexões mais do que apresentando formulações fechadas - é possível detetar algumas das preocupações que perpassam a sua obra ${ }^{13}$.

\footnotetext{
${ }^{11}$ Refiro-me às exposições "Them or us", com a curadoria de Paulo Mendes na Galeria Municipal do Porto em 2017, e, para citar apenas um exemplo dos cruzamentos artísticos e disciplinares a que a curadoria de Nuno Faria nos tem habituado, cito a exposição "Objetos estranhos: ensaio de Proto-escultura", que decorreu no Centro Internacional José de Guimarães, em Guimarães, em 2017.

${ }^{12} \mathrm{Na}$ perspetiva da autora deste texto, essa atitude não deve ser encarada como uma fraqueza, mas como uma marca da sua originalidade, e de uma certa rebeldia contra o academismo em todas as suas formas - artístico e universitário.

${ }^{13}$ É importante sublinhar que o autor apresentava algum conhecimento dos trabalhos anteriormente escritos sobre o tema. Logo em 1964, no texto "Conhecimento da arte moderna e popular", Ernesto de Sousa reconhece que "a descoberta da arte popular em Portugal está num modesto começo" (Sousa, E. (1987) [1964], 36). Mencionando que no campo da música e da arquitetura alguns avanços já foram feitos (na primeira, com Michel Giacometti e Fernando Lopes Graça e, na segunda, com o Inquérito à Arquitetura Popular), sublinha que o mesmo não acontece nas artes plásticas. Lucidamente, refere que "o valioso material acumulado pacientemente pelos etnógrafos não tem sido acompanhado por estudos de
} 
Restivo, Maria Manuela (2020). A emergência da autoria na arte popular portguesa: o contributo de Ernesto de Sousa. In Alice Duarte (ed.), Seminários DEP/FLUP vol. 1. Porto: Universidade do Porto, Faculdade de Letras/DCTP, p. 98-117. https://doi.org/10.21747/9789898969682/seminariosv1a5

É interessante notar, em primeiro lugar, que quando procura uma definição da arte popular, esta é construída em diálogo com a arte erudita, procurando perceber 0 que é próprio de cada uma. Assim, se a arte culta ou erudita "se refere a um arquétipo de beleza, a cânones formais, a arte popular é acima de tudo expressiva" (Sousa (1987) [1964]). Se a primeira apreende formas, a segunda comportamentos. Na produção popular estaria ausente qualquer preocupação de carácter formal, "e a noção abstrata de harmonia é-lhe estranha" (idem, 34). Apesar de serem definidos como domínios separados, afirma que as permutas entre ambos são constantes. Tal permite-Ihe fazer a defesa da arte popular perante os que afirmam que ela é mera imitação ou mesmo deturpação das formas eruditas; o artista popular, mesmo quando se baseia em formas eruditas - o que não será sempre o caso - fá-lo-á criativamente.

Em segundo lugar, Ernesto de Sousa vai estabelecer uma distinção, até então não formulada, entre o artista e o artesão dentro da expressão popular - que se distingue da distinção artista erudito/popular. Assim, no artesão "palpita uma liberdade criadora maior ou menor", mas que é dominado pela imitação (Sousa (2014) [1966], 85), sendo o artista o "verdadeiro criador". "A obra exclusivamente artesanal seria, pois, aquela onde a imitação e a repetição é verdadeiramente anónima, limitando-se a preencher uma função decorativa de objetos usuais, no sentido mais pobre" (idem, 85). Os segundos, são, "regra geral, verdadeiros outsiders, não raras vezes mal vistos pela comunidade" (idem, 85), citando aqui o caso de Douanir Rousseau.

Em terceiro lugar, a ideia de uma autoria. "Nesta fase do nosso trabalho temos já material para demonstrar que nos meios em que situamos a arte "popular" (e em particular nos nossos meios camponeses) existem autênticos artistas individuais, com génio próprio" (Sousa (2014) [1966], 91). Não só a formulação desta ideia é fundamental, como o são as suas efetivações e concretizações: a realização de exposições em que os artistas populares são considerados autores e a redação de monografias individuais acerca de alguns destes artistas. A monografia que realizou sobre Franklin Vilas Boas (não publicada) foi, durante algumas décadas, a única existente dedicada a um artista popular.

natureza estética" (idem). Nos seus textos menciona Vergílio Correia e Leite de Vasconcelos, mas não menciona outros textos sobre a temática, como por exemplo os escritos de Luís Chaves ou outras revistas ligadas ao Estado Novo. 
Restivo, Maria Manuela (2020). A emergência da autoria na arte popular portguesa: o contributo de Ernesto de Sousa. In Alice Duarte (ed.), Seminários DEP/FLUP vol. 1. Porto: Universidade do Porto, Faculdade de Letras/DCTP, p. 98-117. https://doi.org/10.21747/9789898969682/seminariosv1a5

Por fim, o que é fundamental em Ernesto de Sousa é a sua definição de arte popular enquanto essência pura. Ela conterá em si a ideia de origem, de começo absoluto, de primitividade não domada pela razão. Para além dos objetos da arte popular que é importante descobrir e inventariar, segundo Ernesto de Sousa o que devemos retirar da arte popular é sobretudo a sua "força mágica", contida na ideia do ingénuo, do poder "indomado" que ela contém, e que é possível transpor para a produção artística contemporânea. O ingénuo é assim, mais que uma caracterização de um tipo de arte, "uma categoria que participa a graus diversos em toda a criação artística" (Wandschneider, 1998: 86). Desta forma, para Ernesto de Sousa, a arte popular é uma plataforma para a emancipação artística, desígnio fundamental que alimentará o seu percurso profissional a partir de determinada altura, independente dos meios nos quais ela se manifesta ${ }^{14}$. Este aspeto foi já notado por Mariana Pinto dos Santos (2014), que refere que "a sua preocupação não será salvar este tipo de arte popular do fim certo, mas sim absorver-lhe o máximo que lhe puder servir para renovar práticas e conceções artísticas para aplicar no presente" (2014: 125). De facto, não só Ernesto de Sousa foi fulcral para o desenvolvimento da arte popular portuguesa, perspetiva que aqui se procura analisar e defender, como a arte popular foi fundamental para o pensamento de Ernesto de Sousa. Ela é, em suma, uma potência transformadora para a construção de uma arte emancipatória, manifesta sobretudo numa atitude de encarar a criação artística, extensível ao seu próprio percurso biográfico, ou seja, à forma de estar no mundo.

Por isso Ernesto de Sousa a define, num certo momento, como a-histórica (2014: 87). Ela vive fora da diacronia porque é essência pura, e enquanto tal, invariável: “... para o artista popular trata[-se] sempre de um "primeiro encontro", não sofre, portanto, uma evolução, ou não aceita, canonicamente, qualquer evolução. É assim que se mantém fora, ou de fora, das correntes cultas" (2014: 87). O autor refere mesmo que se verifica "uma reversão parcial à anterioridade cultural do artista ingénuo" (idem 87).

Analisando a perspetiva de Ernesto de Sousa sobre a arte popular constatam-se algumas continuidades com o pensamento de autores de épocas anteriores, como é por

\footnotetext{
${ }^{14}$ Esta ideia de origem enquanto começo absoluto e constante, que a arte popular incorporaria, ideia que o próprio estudo da arte popular lhe permitiu formular, condensa a própria atitude que Ernesto de Sousa vai desenvolver perante a sua vida-obra.
} 
Restivo, Maria Manuela (2020). A emergência da autoria na arte popular portguesa: o contributo de Ernesto de Sousa. In Alice Duarte (ed.), Seminários DEP/FLUP vol. 1. Porto: Universidade do Porto, Faculdade de Letras/DCTP, p. 98-117. https://doi.org/10.21747/9789898969682/seminariosv1a5

exemplo a ideia do cogito pré-reflexivo, presente já em Luís Chaves, que relembra a ideia de "mentalidade primitiva". O artista popular, parco de racionalidade, operaria através de uma certa relação intuitiva com o mundo, desconhecendo qualquer regra estética ou plástica. Esta ideia corrobora um certo pensamento romântico e paternalista que vê a arte popular como uma criação idealizada, e que prende o artista popular a um lugar donde ele não pode sair: o da primitividade, não no sentido de básico ou limitado, mas no de primordial ou de "anterioridade cultural"15.

Porém, para além das continuidades com outros autores, a sua obra contribui para uma mudança considerável na forma de conceber a arte popular: esta sai do seu lugar "etnográfico" para se tornar em objeto estético, que João Leal (2004) caracterizou como uma leitura modernista da arte popular. O que vigorou na arte popular durante a primeira metade do século XX, com poucas exceções - o objeto enquanto testemunho de um determinado modo de vida, estreitamente ligado a regiões concretas e como fruto de uma criação coletiva - modifica-se radicalmente no pensamento de Ernesto de Sousa. A arte popular passa a designar, a partir de então, uma criação autoral de indivíduos "ingénuos", porque desconhecedores das normas artísticas eruditas ou académicas. Não se trata já de uma criação coletiva do povo português, porta de acesso à "alma nacional", exaltação do pitoresco característico de cada região; para este autor, a arte popular é, de facto, arte, proveniente de um universo criativo singular que importa valorizar. Consequentemente, realiza-se o deslocamento no que diz respeito aos objetos de arte popular em que se vai focar: não lhe interessam as rendas, os bordados ou as olarias, nem mesmo outras manifestações mais "artísticas", como os exvotos pintados, que tantos adeptos apresenta do ponto de vista estético, mas sobretudo a escultura (Leal, 2004).

\footnotetext{
${ }^{15}$ Esta forma de encarar a arte popular, como já foi reconhecido por Mariana Pinto dos Santos (2014) e João Leal (2004), enquadra-se na corrente primitivista - uma projeção sobre o outro e a sua arte, baseado na procura de uma essência original ou primordial, autêntica, não tocada pela civilização, utilizada na sua possibilidade de oposição ao academismo artístico. Se há inegavelmente um pensamento primitivista em Ernesto de Sousa, ele não pode ser encarado unicamente na sua versão colonialista, antes devendo ser considerado na capacidade crítica que o seu primitivismo pressupõe, tema que se irá abordar na investigação de doutoramento em curso.
} 
Restivo, Maria Manuela (2020). A emergência da autoria na arte popular portguesa: o contributo de Ernesto de Sousa. In Alice Duarte (ed.), Seminários DEP/FLUP vol. 1. Porto: Universidade do Porto, Faculdade de Letras/DCTP, p. 98-117. https://doi.org/10.21747/9789898969682/seminariosv1a5

\section{Conclusão}

No presente capítulo procurou-se refletir sobre o contributo de Ernesto de Sousa para a arte popular portuguesa, através da análise da investigação e ação cultural (exposições, palestras, debates) que dedicou a esta forma de arte. Quando comparado com as gerações anteriores, ou mesmo com alguns autores seus contemporâneos (por exemplo Pires de Lima no livro A Arte Popular em Portugal (1968)), Ernesto de Sousa introduz algumas alterações fundamentais na forma de perspetivar a arte popular: esta passa a ser associada a autores específicos - Rosa Ramalho, Franklin Vilas Boas, Mistério - portadores de uma obra única e singular, contrariando a ideia de que se trata de uma criação coletiva. Ainda que o seu pensamento apresente algumas continuidades com autores de gerações anteriores (como por exemplo Luís Chaves), ele introduz descontinuidades consideráveis, sendo em Portugal um dos primeiros a defender e a propagar a ideia de autoria na arte popular portuguesa.

A emergência da autoria na arte popular implicará algumas modificações: as peças, fundamentalmente utilitárias, valorizadas pelas gerações anteriores - olarias, rendas, bordados, etc - dão lugar a objetos com uma forte componente escultórica, aproximando-se do universo das Belas Artes. A visão pitoresca e regionalista da arte popular, propagada durante tanto tempo pelo regime do Estado Novo, dá lugar a uma arte popular de autor, em que os artistas são valorizados pela sua singularidade. À semelhança dos artistas eruditos, os artistas populares começam a ser alvo de monografias e exposições individuais ou coletivas - como ocorreu nas galerias Divulgação e Alvarez - inaugurando-se um novo circuito de divulgação, circulação e consumo da arte popular em Portugal.

\section{Referências Bibliográficas}

Alves, V. M. (2013). Arte popular e nação no Estado Novo. Lisboa: Imprensa de Ciências Sociais.

Becker, H.S. (2010). Mundos da arte. Lisboa: Livros Horizonte. 
Restivo, Maria Manuela (2020). A emergência da autoria na arte popular portguesa: o contributo de Ernesto de Sousa. In Alice Duarte (ed.), Seminários DEP/FLUP vol. 1. Porto: Universidade do Porto, Faculdade de Letras/DCTP, p. 98-117. https://doi.org/10.21747/9789898969682/seminariosv1a5

Bragança, M. M. (2016). Francisco Lage, um intelectual: ideia e ação na etnografia e cultura popular (1935-1948). Tese de doutoramento. Lisboa: Faculdade de Ciências Sociais e Humanas da Universidade Nova de Lisboa.

Brito, J.P. [coord.] (1995). Onde mora o Franklim? Um escultor do acaso. Catálogo de Exposição. Lisboa: Instituto Português de Museus/ Museu Nacional de Etnologia.

Canclini, N. G. (1989). Culturas híbridas: Estrategias para entrar y salir de la modernidad. Cidade do México: Grijalbo.

Chaves, L. (1914). A coleç̧ão de «milagres» do Museu Etnológico Português. O Arqueólogo Português, n. 19, p. 152-176.

Chaves, L. (1936). Para uma exposição de Arte Popular Portuguesa. In SPN, Catálogo da exposição de arte popular portuguesa. Lisboa: SPN.

Chaves, L. (1940). Roteiro do Centro Regional: Exposição do Mundo Português. Lisboa: Secretariado da Propaganda Nacional.

Chaves, L. (1943). Arte popular. Aspetos do problema. Coleção Biblioteca Popular. Porto: Portucalense Editora.

Correiaa, V. (1915a). Arte popular portuguesa I. A Águia, 2. a série, n. 39, p. 117-123.

Correia, V. (1915b). Arte popular portuguesa II. A Águia, 2.a série, n. 45, p. 97-106.

Correia, V. (1915c). Arte popular portuguesa III. A Águia, 2. a série, n. 48, p. 239-249.

Correia, V. (1916a). Etnografia artística. Notas de etnografia portuguesa e italiana. Porto: Edição da Renascença Portuguesa.

Correia, V. (1916b). 'Cassoiros' do Baixo Alentejo. Terra Portuguesa, n. I, p. 63.

Correia, V. (1916c). Brinquedos de Louça de Estremoz. Terra Portuguesa, n. I, p. 80.

Correia, V. (1916d). 'Tarros' do Alentejo e da Beira-Baixa. Terra Portuguesa, n. I, p. 9394.

Faria, N. (ed.) (2014). Ernesto de Sousa e a arte popular. Em torno da exposição Barristas e Imaginários. Guimarães: A oficina/ Sistema Solar.

Fernandes, J e Ramos, M. (coord.) (1997). Perspectiva: Alternativa zero. Porto: Fundação de Serralves.

França, J.A. (1997). Alternativa Zero em seu tempo. In J. Fernandes e M. Ramos (coord.) Perspectiva: Alternativa zero. Porto: Fundação de Serralves, p. 37-45.

Leal, J. (2004). Metamorfoses da arte popular: Joaquim de Vasconcelos, Vergílio Correia e Ernesto de Sousa. Etnográfica, vol. VI, n. 2, p. 251-280. 
Restivo, Maria Manuela (2020). A emergência da autoria na arte popular portguesa: o contributo de Ernesto de Sousa. In Alice Duarte (ed.), Seminários DEP/FLUP vol. 1. Porto: Universidade do Porto, Faculdade de Letras/DCTP, p. 98-117. https://doi.org/10.21747/9789898969682/seminariosv1a5

Leal, J. (2006). Antropologia em Portugal: mestres, percursos, tradições. Lisboa: Livros Horizonte.

Leandro, S. (2014). Joaquim de Vasconcelos: Historiador, crítico de arte e museólogo. Uma ópera. Lisboa: Instituto Nacional Casa da Moeda.

Leite de Vasconcelos, J. (1881). Estudo ethnographico. A propósito da ornamentação de jugos e cangas de bois nas províncias portuguesas de Douro e Minho. Porto: Empreza do Jornal d'Agricultura Editora.

Leite de Vasconcelos, J. (1915). História do Museu Etnológico Português (1893-1914). Lisboa: Imprensa Nacional Casa da Moeda.

Leite de Vasconcelos, J. (1920-1938). Boletim de etnografia. Lisboa: Imprensa Nacional.

Leite de Vasconcelos, J. (1933-1988). Etnografia portuguesa. Tentame de sistematização. Lisboa: Imprensa Nacional Casa da Moeda, 10 vols.

Melo, D. (2001). Salazarismo e cultura Popular. Lisboa: ICS.

Morris, W. (2003). Artes Menores. Lisboa: Antígona.

Peixoto, R. (1995). Etnografia Portuguesa. Obra Etnográfica completa. Lisboa: Publicações Dom Quixote.

Pessanha, S. (1916). A fiacção e a tecelagem manuaes em Portugal - Os tecelões paramenteiros de Braga I. Terra Portuguesa, Revista llustrada de Arqueologia Artística e Etnografia, vol. 2, n. 8.

Pires de Lima, F. (1968). Arte Popular em Portugal: Ilhas adjacentes e Ultramar. Volume I. Lisboa: Editorial Verbo.

Restivo, M. M. (2016). A Arte Popular da família Ramalho. Catálogo de Exposição. In Cruzes Canhoto (ed.), Lagarto, lagarto, lagarto (s/p). Porto: Cruzes Canhoto.

Ribeiro, E. (1997) [1923]. O doce nunca amargou. Sintra: Colares Editora.

Ribeiro, E. (1999) [1933]. A arte do papel recortado em Portugal. Sintra: Colares Editora.

Rousseau, Valérie (2012). Vers une définition de l'art populaire: l'institution problématique d'une notion polysémyque. L'axe France-Canada dans une perspective européene et nord-americaine. Montréal: Université du Québec. Tese de Doutoramento.

Santos, M. P. (2007). Vanguarda \& outras loas. Percurso teórico de Ernesto de Sousa. Lisboa: Assírio e Alvim.

Santos, M. P. (2014). Encontrar a cadencia. In N. Faria (ed.), Ernesto de Sousa e a Arte Popular. Guimarães: CIAJG, p. 99-129. 
Restivo, Maria Manuela (2020). A emergência da autoria na arte popular portguesa: o contributo de Ernesto de Sousa. In Alice Duarte (ed.), Seminários DEP/FLUP vol. 1. Porto: Universidade do Porto, Faculdade de Letras/DCTP, p. 98-117. https://doi.org/10.21747/9789898969682/seminariosv1a5

Shelton, A. A. (2015). Heaven, hell and somewhere in between. Portuguese popular art. Vancouver: MOA/University of British Columbia.

Sousa, E. (1987) [1964]. Barristas e imaginários. Quatro artistas populares do norte. Catálogo de exposição. In C. Gentil-Homem e J.C. Rocha (orient.). Ernesto de Sousa - Itinerários. Lisboa: Secretaria de Estado da Cultura.

Sousa, E. (1987) [1964]. Conhecimento da arte moderna e popular. In C. Gentil-Homem e J.C. Rocha (orient.), Ernesto de Sousa - Itinerários. Lisboa: Secretaria de Estado da Cultura, p. 33-37.

Sousa, Ernesto (1973) [1965]. Para o estudo da escultura portuguesa. Lisboa: Livros Horizonte.

Sousa, Ernesto [2014] (1966). Relatório de trabalho efetuado nos meses de Outubro, Novembro e Dezembro de 1966. In N. Faria (ed.), Ernesto de Sousa e a Arte Popular. Guimarães: CIAJG, p. 49-95.

Sousa, E. (1987) [1970]. A arte popular e a arte ingénua. In C. Gentil-Homem e J.C. Rocha (orient.), Ernesto de Sousa - Itinerários. Lisboa: Secretaria de Estado da Cultura, p. 38-44.

Sousa, E. (1998). Ser moderno... em Portugal. Lisboa: Assírio e Alvim.

Vogel, S. (1988). Art/artifact. Munich: Prestel.

Wandschneider, M. (1998). Descontinuidade biográfica e invenção do autor. In Fundação Calouste Gulbenkian (coord.), Ernesto de Sousa - Revolution my body. Lisboa: Fundação Calouste Gulbenkian/Centro de Arte Moderna José de Azeredo Perdigão, p. 14-24.

Wandschneider, M. (1998). Notas biográficas e fragmentos para uma autobiografia involuntária. In Fundação Calouste Gulbenkian (coord.), Ernesto de Sousa Revolution my body. Lisboa: Fundação Calouste Gulbenkian/Centro de Arte Moderna José de Azeredo Perdigão, p. 39-121. 